\title{
The yield strength of thin copper films on Kapton
}

\section{Citation}

Yu, Denis Y. W., and Frans Spaepen. 2004. "The Yield Strength of Thin Copper Films on Kapton." Journal of Applied Physics95 (6): 2991-97. https://doi.org/10.1063/1.1644634.

\section{Permanent link}

http://nrs.harvard.edu/urn-3:HUL.InstRepos:41511313

\section{Terms of Use}

This article was downloaded from Harvard University's DASH repository, and is made available under the terms and conditions applicable to Other Posted Material, as set forth at http:// nrs.harvard.edu/urn-3:HUL.InstRepos:dash.current.terms-of-use\#LAA

\section{Share Your Story}

The Harvard community has made this article openly available.

Please share how this access benefits you. Submit a story.

Accessibility 


\title{
The yield strength of thin copper films on Kapton
}

\author{
Denis Y. W. Yu and Frans Spaepen ${ }^{\text {a) }}$ \\ Division of Engineering and Applied Sciences, Harvard University, Cambridge, Massachusetts 02138
}

(Received 7 October 2003; accepted 8 December 2003)

Thin films of copper, with thickness between 0.1 and $3 \mu \mathrm{m}$, were vapor-deposited on 12.7 or 7.6- $\mu \mathrm{m}$-thick polyimide (Kapton) substrates. They were tested in a microtensile tester in which the strain is measured by optical diffraction from a microlithographically applied grid. The Young modulus is independent of film thickness and is about $20 \%$ below the value calculated from single-crystal elastic constants. The yield stress depends strongly on the film thickness and is fit by $\sigma_{y}=116+355(t)^{-0.473}$, where $t$ is the thickness in $\mu \mathrm{m}$ and $\sigma_{y}$ is in $\mathrm{MPa}$. The microstructure of the films was studied by focused ion-beam microscopy. The grains are heavily twinned and the microstructural lengths (grain size, twin spacing, twin width) depend only weakly on the film thickness. A substantial part of the yield stress is therefore attributable to an effect of the film thickness, such as that predicted by strain gradient plasticity theory. The lower limit and some estimates of the thickness contribution to the yield stress are calculated. The estimated characteristic length of strain gradient plasticity theory is $0.6 \mu \mathrm{m}$ for these materials. (C) 2004 American Institute of Physics. [DOI: 10.1063/1.1644634]

\section{INTRODUCTION}

The yield strength of metallic films is affected by several microstructural dimensions: grain size, film thickness, and obstacle spacing. Studies of the effect of dimensional constraints on mechanical properties are complicated by the interdependence of the microstructure and the deposition conditions. The purpose of this study is to investigate the relationships among yield strength, film thickness, and microstructure under constant deposition conditions.

The yield strength can be measured by a variety of methods, such as tensile testing, indentation, microbeam bending, and bulge testing. ${ }^{1-4}$ We use a microtensile tester of our own design (see Fig. 1). Even though this method is experimentally somewhat more complex than most of the others, its main advantage is that it provides basic mechanical parameters directly, without the need for model-based data analysis. All our tensile testing so far has been on freestanding thin films. ${ }^{5}$ Because of sample preparation and handling, testing of freestanding films with thickness less than $3 \mu \mathrm{m}$ is difficult. One method to test thinner freestanding films uses Si supporting frames. ${ }^{6-12}$ These frames are severed immediately before testing to leave the film freestanding. This method requires complex sample preparation, such as patterning and etching.

Alternatively, thin films on compliant polymer substrates (polyimide foils) can be tested. The polyimide foils can be handled easily during sample preparation. To obtain the properties of the film, the properties of the substrate are subtracted from the overall measurement. Using this method, the mechanical properties of metallic films $[\mathrm{Al}, \mathrm{AlCu}$, $\mathrm{CuNi}(\mathrm{Mn}), \mathrm{Cu}$, etc.] on Kapton ${ }^{13-20}$ and pyromellitic dianhydride oxydianiline (PMDA-ODA) $)^{21-25}$ have been studied. In several of these studies, an increase of the yield strength

\footnotetext{
${ }^{a)}$ Electronic mail: spaepen@deas.harvard.edu
}

with decreasing film thickness has been observed. The functional dependence of this increase and its physical origin have still not been definitely established.

This study adds to the data in this area by applying a particular experimental method and by paying special attention to the microstructure, including details such as the twins and twin spacing.

\section{EXPERIMENTAL TECHNIQUES}

$\mathrm{Cu}$ thin films with thicknesses of 0.1-3 $\mu \mathrm{m}$ were deposited through a dogbone-shaped mask on rectangular Kapton substrates $(8 \mathrm{~mm} \times 45 \mathrm{~mm})$ by electron-beam evaporation. The deposition rate was $5 \AA / s$. Cu adheres well to Kapton. A square array of photoresist islands with spacing of $10 \mu \mathrm{m}$ is patterned on the $\mathrm{Cu} /$ Kapton layers to act as a diffraction grating for strain measurement. ${ }^{26}$

The samples were tested in the apparatus shown in Fig. 1. 5,26,27 The strain is measured using optical diffraction from the photoresist islands by transmission through the bare Kapton. Strain measurements on some of the films by diffraction in reflection, as in earlier work, ${ }^{5}$ gave results identical to those measured in transmission. The transmission mode was preferred because it gave sharper diffraction and is less susceptible to misalignment and wrinkling. The total force on the system is the sum of the forces on the copper and Kapton, and is measured by a load cell attached to the end of the sample stage. All the tests were done at room temperature at a strain rate of $5 \times 10^{-5} \mathrm{~s}^{-1}$. The thickness of the $\mathrm{Cu}$ films was determined by Rutherford backscattering using $4 \mathrm{MeV}$ $\mathrm{He}$ ions for $\mathrm{Cu}$ films thicker than $1.5 \mu \mathrm{m}$, and $2 \mathrm{MeV}$ for thicknesses less than $1.5 \mu \mathrm{m}$.

Kapton foils with nominal thicknesses of $12.7 \mu \mathrm{m}$ (grade 50HN) and $7.6 \mu \mathrm{m}$ (grade 30HN) were tested. However, due to systematic errors in the measurement at large strain for the $7.6 \mu \mathrm{m}$ Kapton foils (probably caused by wrin- 


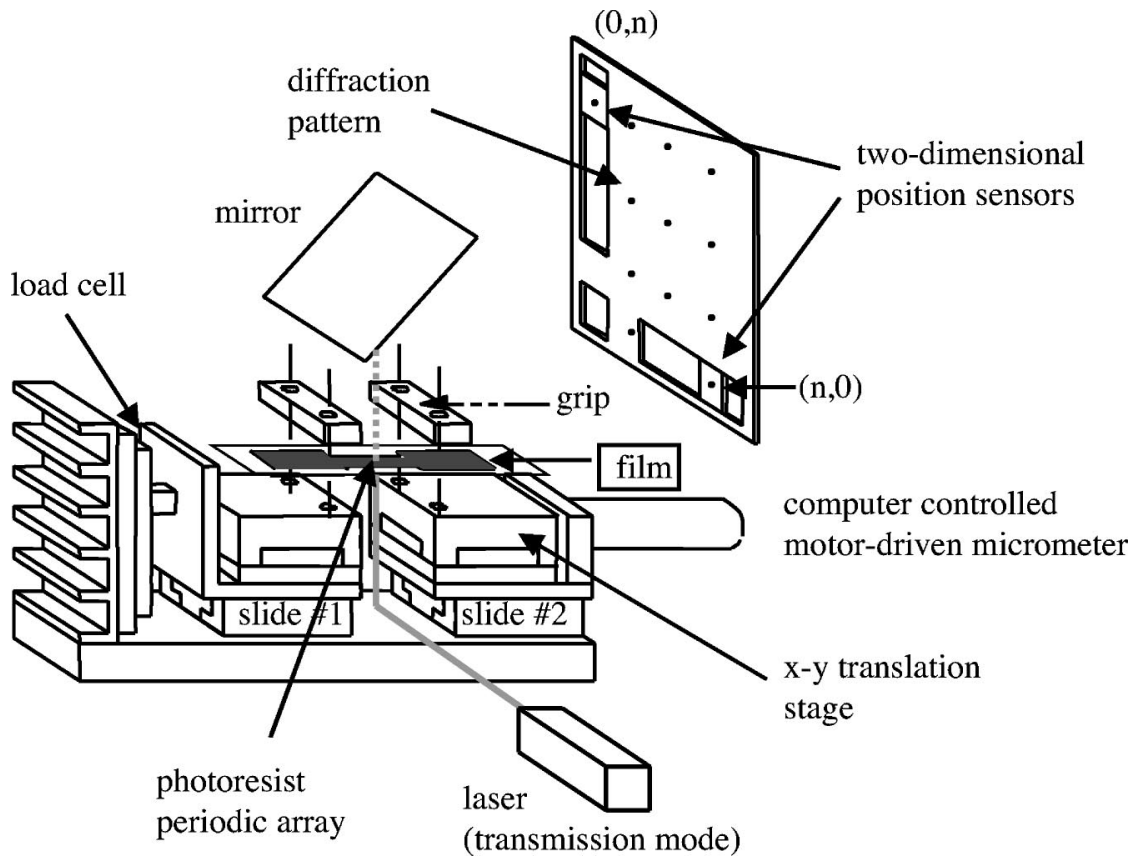

FIG. 1. Schematic diagram of the microtensile tester.

kling), only the 12.7- $\mu$ m-thick Kapton was used for the yield measurements.

\section{RESULTS}

\section{A. Kapton foils}

Rectangular Kapton foils with widths between 6 and 10 $\mathrm{mm}$ and a length of $45 \mathrm{~mm}$ were tested. The stress-strain curves are reproducible, and an example for a $12.7 \mu \mathrm{m}$ Kapton foil is shown in Fig. 2. The foil is elastic up to a strain of $0.8 \%$. The total strain was $4 \%$. Even though the Kapton can sustain much larger strains, such strains could not be imposed because of the limitation of the force in the tester. Young's moduli of Kapton foils with the photoresist islands were determined from the unloading lines, and the values are listed in Table I. Poisson's ratio was determined from the ratio of the transverse to longitudinal strain within the elastic limit (see Table I). Measurements of Poisson's ratio in our microtensile tester on freestanding $\mathrm{Cu}$ films are not reliable because of transverse wrinkling. ${ }^{28}$ Measurements for Kapton

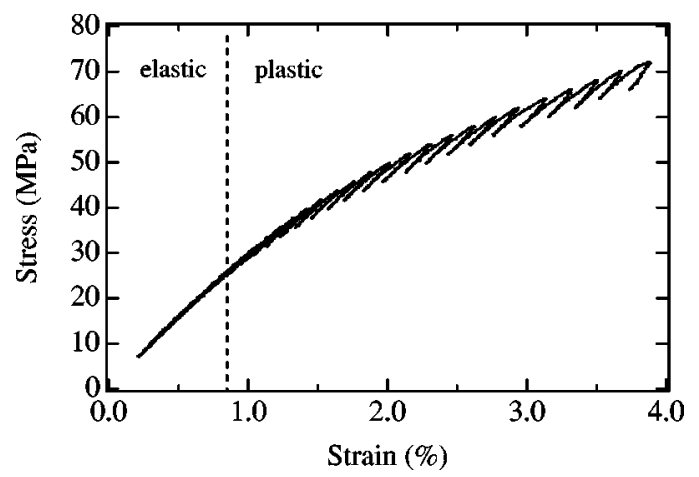

FIG. 2. Stress-strain curve of a 12.7- $\mu$ m-thick Kapton foil. The foil is unloaded periodically. Unloading allows the identification of the yield point and the slope of the unloading line gives the Young modulus. are more reliable because the transmission mode of the strain measurement is less susceptible to effect of wrinkling.

For plastic deformation, the stress-strain curves of several Kapton foils were averaged and the result was fitted with a fifth-order polynomial, with constraints

$$
\left.\sigma\right|_{\varepsilon=0}=0 \quad \text { and }\left.\quad \frac{d \sigma}{d \varepsilon}\right|_{\varepsilon=0}=E_{\text {Kapton }} .
$$

The result for $12.7 \mu \mathrm{m}$ Kapton foils is

$$
\sigma_{\text {Kapton }}=34 \varepsilon-2.732 \varepsilon^{2}-1.287 \varepsilon^{3}+0.254 \varepsilon^{4},
$$

where $\sigma_{\text {Kapton }}$ is in $\mathrm{MPa}$ and $\varepsilon$ is in percent. The error in the fit is $1 \mathrm{MPa}$ at $\varepsilon=1 \%$. The polynomial form is convenient for the analysis of the $\mathrm{Cu}$ data.

\section{B. Copper films}

The strain applied to both the $\mathrm{Cu}$ and Kapton films is the same, and the measured force is the sum of the forces on both layers:

$$
F_{\text {total }}=F_{\mathrm{Cu}}+F_{\text {Kapton }} .
$$

Force-strain curves of $\mathrm{Cu} / \mathrm{Kapton}$ with different $\mathrm{Cu}$ thicknesses are shown in Fig. 3. The modulus and yield strength of the $\mathrm{Cu}$ film as a function of film thickness were obtained.

\section{Young's modulus}

The modulus of the $\mathrm{Cu}$ film is obtained from the elastic unloading by

$$
E_{\mathrm{Cu}}=\frac{1}{w_{\mathrm{Cu}} t_{\mathrm{Cu}}}\left(\frac{\Delta F_{\text {total }}}{\Delta \varepsilon_{\mathrm{el}}}-\frac{\Delta F_{\text {Kapton }}}{\Delta \varepsilon_{\mathrm{el}}}\right),
$$

where $w_{\mathrm{Cu}}$ and $t_{\mathrm{Cu}}$ are, respectively, the width and thickness of the $\mathrm{Cu}$ film, and $\Delta F / \Delta \varepsilon_{\mathrm{el}}$ is the slope of the force-strain unloading lines. Equation (4) is derived assuming that the effect from the difference in the Poisson ratio between the two layers is negligible. ${ }^{27}$ The Young modulus of $\mathrm{Cu}$ is in- 
TABLE I. Elastic properties of Kapton substrates and $\mathrm{Cu}$ films on Kapton. The error for $E_{\mathrm{Cu}}$ corresponds to the data for the films of all thicknesses.

\begin{tabular}{ccccc}
\hline \hline Substrate & $\begin{array}{c}\text { Substrate } \\
\text { thickness }(\mu \mathrm{m})\end{array}$ & $\begin{array}{c}E_{\text {Kapton }} \\
(\mathrm{GPa})\end{array}$ & $\begin{array}{c}E_{\mathrm{Cu}} \\
(\mathrm{GPa})\end{array}$ & $\nu_{\text {Kapton }}$ \\
\hline Kapton $50 \mathrm{HN}$ & 12.7 & $3.4 \pm 0.1$ & $108.8 \pm 11.7$ & $0.335 \pm 0.121$ \\
Kapton 30HN & 7.6 & $3.5 \pm 0.1$ & $97.2 \pm 7.3$ & $0.328 \pm 0.058$ \\
free-standing Cu & $\cdots$ & $\cdots$ & $102 \pm 7$ & $\cdots$ \\
\hline \hline
\end{tabular}

${ }^{\mathrm{a}}$ See Ref. 28.

dependent of film thickness, and the average value is 108.8 GPa for 12.7- $\mu \mathrm{m}$-thick Kapton and 97.2 GPa for 7.6- $\mu \mathrm{m}$ thick Kapton (see Fig. 4 and Table I). The difference is not statistically significant. For $\mathrm{Cu}$ on 12.7- $\mu \mathrm{m}$-thick Kapton, the error for the modulus is $2.5 \mathrm{GPa}$ for $2 \mu \mathrm{m} \mathrm{Cu}$ and $25 \mathrm{GPa}$ for $0.2 \mu \mathrm{m} \mathrm{Cu}$. This spread of data can be seen in Fig. 4. The error for the modulus of $\mathrm{Cu}$ with the 7.6- $\mu$ m-thick Kapton is smaller.

The measured modulus is similar to the value obtained for $3 \mu \mathrm{m}$ freestanding $\mathrm{Cu}$ films by the same deposition and testing method: $102 \pm 7 \mathrm{GPa} .{ }^{28}$ The texture of the supported film was measured by $\mathrm{x}$-ray diffraction and was found to be similar to that of the freestanding films: predominantly $\langle 111\rangle$, with the $\langle 100\rangle$ orientation stronger than average. A calculation of the modulus based on the measured texture and on single-crystal elastic constants gives $120 \mathrm{GPa}^{27}$ The $20 \%$ modulus deficit observed in these supported films is similar to that reported in other freestanding and multilayered films, ${ }^{5,9,29}$ and has been attributed to grain boundary cracks ${ }^{5}$ and dislocation anelasticity. ${ }^{27,30}$

\section{Yield strength}

The stress in the $\mathrm{Cu}$ film is obtained by subtracting the contribution of the substrate from the total force:

$$
\sigma_{\mathrm{Cu}}=\frac{1}{w_{\mathrm{Cu}} t_{\mathrm{Cu}}}\left(F_{\text {total }}-F_{\text {Kapton }}\right) \text {. }
$$

The resulting stress-strain curves for $\mathrm{Cu}$ of different thicknesses on 12.7- $\mu$ m-thick Kapton are shown in Fig. 5. The yield strength is defined as the stress that gives a plastic strain of $0.2 \%$. Figure 6 is a plot of the yield strength versus film thickness. The error for the yield strength is $10 \mathrm{MPa}$ for

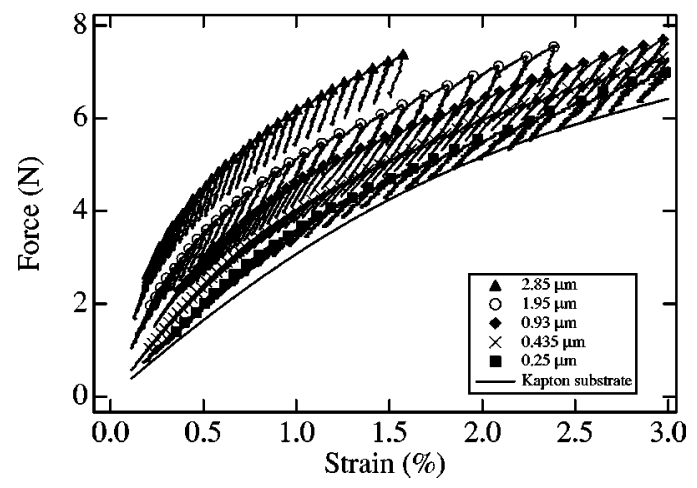

FIG. 3. Force-strain curves of $\mathrm{Cu}$ films of different thickness on 12.7- $\mu \mathrm{m}$ thick Kapton substrates. The short, straight lines correspond to partial unloading. The solid line is the force-strain curve of Kapton substrate.
$3 \mu \mathrm{m} \mathrm{Cu}$ and $120 \mathrm{MPa}$ for $0.2 \mu \mathrm{m} \mathrm{Cu}$. Note that the results from $\mathrm{Cu}$ on Kapton overlap with our measurements on thicker freestanding $\mathrm{Cu}$ films and are close to those obtained by Kraft et al. ${ }^{20,31}$ A least-squares fit of

$$
\sigma_{y}=\sigma_{\mathrm{o}}+k t^{-n}
$$

to the data gives $\sigma_{\mathrm{o}}=116 \mathrm{MPa}, k=355 \mathrm{MPa} \mu \mathrm{m}^{n}$, and $n$ $=0.473$.

\section{Microstructure}

Focused ion-beam (FIB) images of the top surfaces of a $1.95 \mu \mathrm{m}$ and a $0.47 \mu \mathrm{m} \mathrm{Cu}$ film on Kapton are shown in Fig. 7. The average grain size of the two films is similar $(\sim 1.3$ $\mu \mathrm{m})$. The thinner film, however, has thinner twins and a higher twin density.

To study the variation of microstructure across the film thickness further, a profile of the film was obtained by making a shallow wedge $\left(\sim 8^{\circ}\right)$ of a 2.75 and a $1.95 \mu \mathrm{m} \mathrm{Cu}$ film using the FIB, as shown in Fig. 8. The intercept method is used at different distances from the bottom of the film to determine the average twin size. The twin width and the twin spacing were taken as the perpendicular width of the narrow twins and the distance between those twins, respectively.

The variation of these length scales with distance from the bottom is shown in Fig. 9. The average twin size, width, and spacing increase approximately linearly with distance from the bottom of the film. For the same deposition conditions, the average twin size, twin width, and spacing of the top surface are larger for thicker samples.

The grain size at the top of several films was measured from FIB images, such as those of Fig. 7. The grains were identified by the direction of the twin boundaries and were

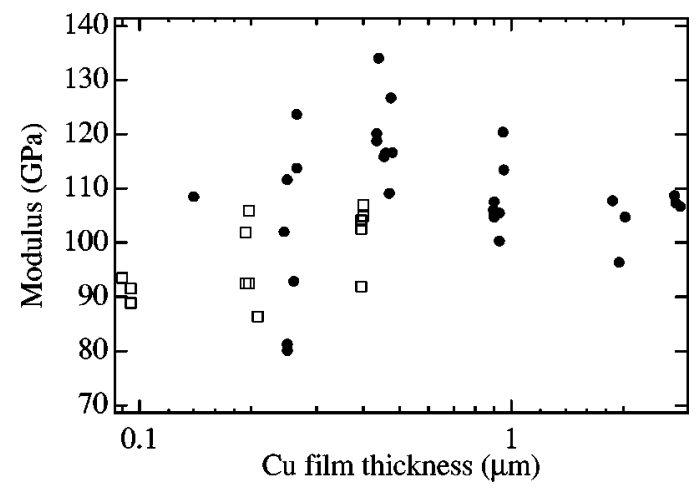

FIG. 4. Young's modulus of $\mathrm{Cu}$ films with different film thicknesses on Kapton substrates ( $12.7 \mu \mathrm{m}$ Kapton; $\square$ : $7.6 \mu \mathrm{m}$ Kapton). 


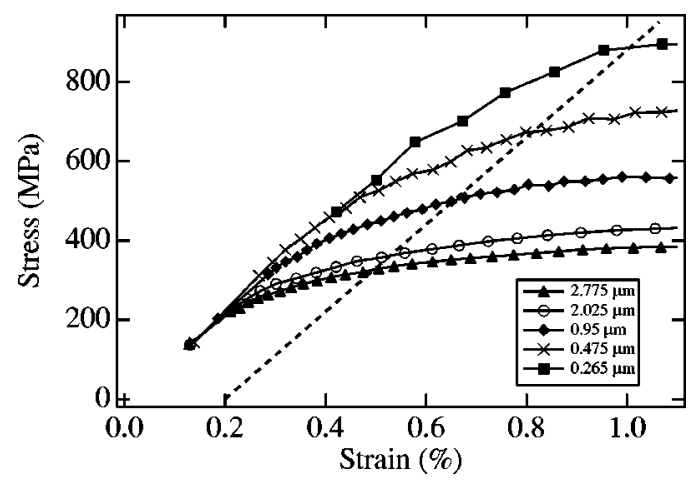

FIG. 5. Stress-strain curves of $\mathrm{Cu}$ films on 12.7- $\mu$ m-thick Kapton substrates, obtained by subtracting the effect of the Kapton substrate. The dashed line has a slope of $108.8 \mathrm{GPa}$, the average Young modulus of the $\mathrm{Cu}$ film, and marks the yield stress at $0.2 \%$ plastic strain.

outlined by hand. The average size was determined by the intercept method. The results are shown in Fig. 9.

\section{DISCUSSION}

A common approach to the quantification of the role of different parts of the microstructure to the yield stress is to assume that their contributions have a power-law form and can be superimposed:

$$
\sigma_{y}=\sigma_{\mathrm{o}}+k d^{-n}+k^{\prime} t^{-m},
$$

where the first term represents the bulk yield stress (largegrained polycrystal), the second one the contribution from the grain boundaries ( $d$ : grain size), and the third one the contribution from the film surface or interface ( $t$ : film thickness).

The first two terms together form the well-known HallPetch (HP) relation, in which, commonly, $n=0.5$. The classical theoretical arguments for the value of this exponent are based on dislocation source activation by pile-ups at the boundaries ${ }^{32,33}$ or on work hardening by dislocations emitted from the grain boundaries. ${ }^{34}$ In thin films with very fine grains $(d \ll t)$ or in multilayers with very thin constituent layers, the deposition of individual dislocation segments becomes more important than the formation of pile-ups, which makes $n$ approach $1.35,36$

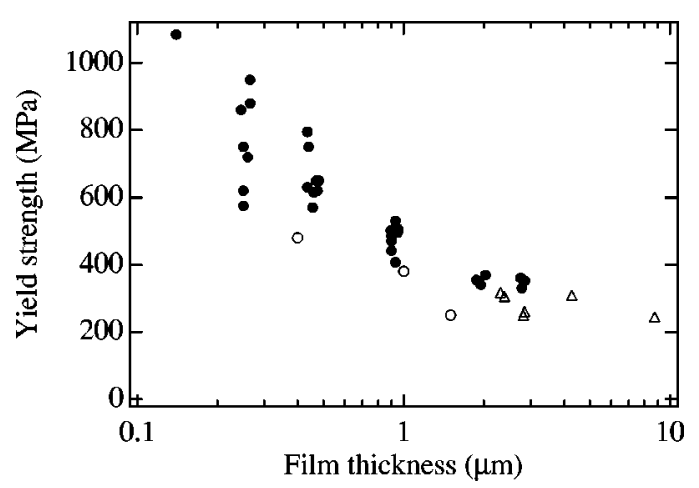

FIG. 6. Yield strength of the $\mathrm{Cu}$ films vs film thickness [O: $\mathrm{Cu}$ on 12.7$\mu \mathrm{m}$-thick Kapton; $\triangle$ : freestanding, as-deposited, $\mathrm{Cu}$ films; $\mathrm{O}$ : data from Kraft et al. (see Ref. 20)]. (a)

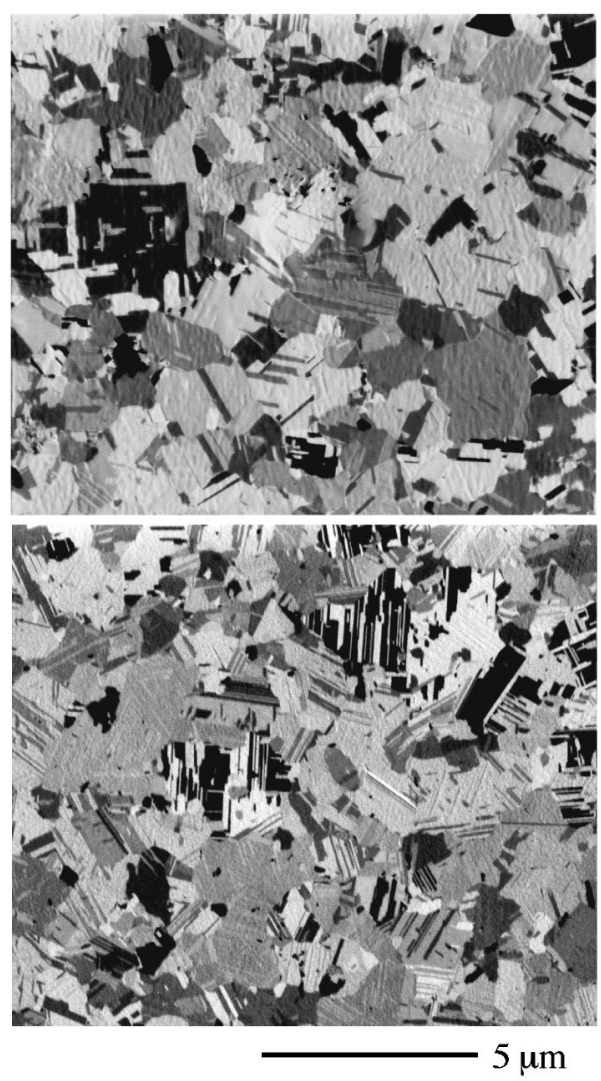

FIG. 7. FIB images of the top surface of a $1.95 \mu \mathrm{m}$ (a) and a $0.47 \mu \mathrm{m}$ (b) $\mathrm{Cu}$ film on Kapton.

The origin of the hardening induced by the finite size of the film is the deposition of dislocation segments at the film surface (if oxidized or otherwise passivated) and at the filmsubstrate interface. An analysis by Nix, ${ }^{4}$ based on work by Freund, ${ }^{37}$ gives an exponent $m$ close to 1 . A similar result is obtained from continuum mechanics by invoking strain gradients in plasticity theory: $:^{38}$ the blocking of the dislocations at the film-substrate interface leads to an inhomogeneous strain distribution, in which the plastic strain approaches zero near the interface. An analysis by Hutchinson ${ }^{39}$ shows that the yield stress depends linearly on the parameter $l / t$, where $l$ is a characteristic length in the theory of strain gradient plasticity: ${ }^{40}$

$$
\frac{\sigma_{y}}{\sigma_{\mathrm{o}}^{\prime}}=1.39+1.80\left(\frac{l}{t}\right)
$$

where $\sigma_{\mathrm{o}}^{\prime}$ is a scaling value close to the bulk yield stress.

A similar picture arises from the discrete dislocation simulations by Nicola, Van der Giessen, and Needleman of thermomechanical deformation of single-crystal thin films on a rigid substrate. ${ }^{41}$ They find a heavily stressed layer near the interface with thickness that does not scale with the film thickness and hence gives rise to a thickness effect. The exponent $m$ varies from 0.5 for the thicker films to 1 for the thinner ones. Recently, they investigated films with a columnar grain structure, ${ }^{42}$ and found additional strengthening superimposed onto the thickness effect; the exponent $n$ has not yet been determined. 


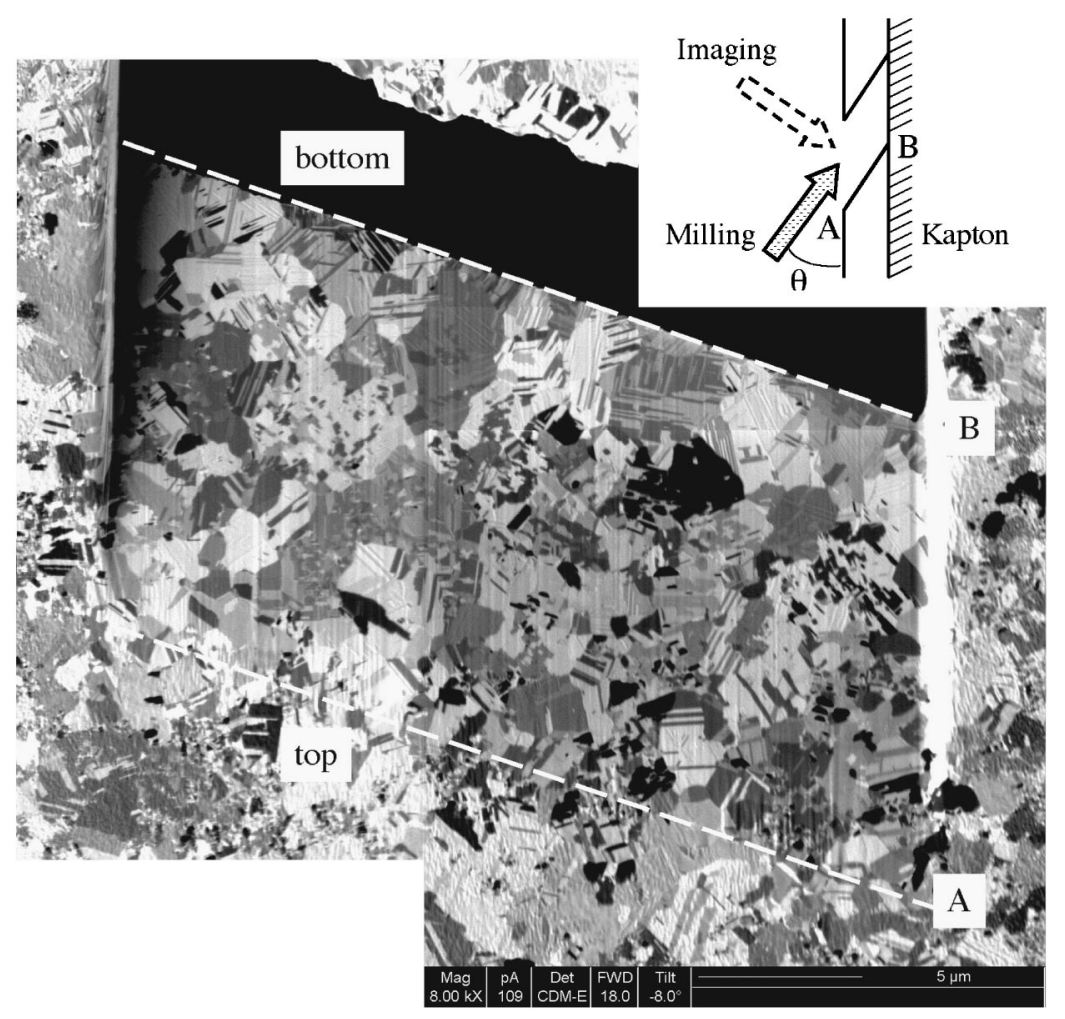

FIG. 8. FIB image of a wedge $\left(\Theta \sim 8^{\circ}\right)$ of a $2.75 \mu \mathrm{m}$ $\mathrm{Cu}$ film on Kapton. Inset: schematic side view of the milling and imaging geometry.

On the experimental side, Venkatraman and Bravman ${ }^{43}$ first separated the effects of grain size and film thickness by electrolytically thinning Al films on Si substrates, and testing them by thermomechanical cycling. They found $m=1$ for the thickness effect, and although they used the HP analysis $(n=0.5)$ for the grain size effect, they found that $n=1$ may have been a more plausible exponent.

The Stuttgart group has investigated $\mathrm{Cu}$ films on both stiff and compliant substrates. Keller et al. ${ }^{44}$ used substrate curvature measurements to measure the room-temperature stress after thermal cycling. They interpreted their results as a superposition of a thickness effect, with $m=1$, and a HP effect $(n=0.5)$. Hommel et al. ${ }^{17,18}$ and Kraft et al. ${ }^{20}$ used $\mathrm{x}$-ray diffraction during tensile testing of samples on compliant substrates, but were not able to separate the effects of grain size and film thickness unambiguously due to the variation of the grain size with thickness and the small range of grain sizes in films with constant thickness.

The striking feature of our data is the weak dependence of the microstructural lengths on the film thickness. As Fig. 9 shows, for a change in film thickness by an order of magnitude, the change in a microstructural length (twin spacing) is only a factor of 2 . The strong variation of the yield stress in Fig. 6 must therefore be predominantly a thickness effect. The following is a calculation of the lower limit and some estimates of the thickness contribution to the yield stress. This will be done by computing the contributions of the microstructure using the HP relation. The twin widths will not be considered because the narrow twins represent only a small volume fraction and need not yield to achieve plastic flow. We will consider the grain size (the traditional HP parameter) and the twin spacing (the most plausible controlling length in this microstructure).
The maximum contribution of the microstructure to the yield stress is computed by assuming that for the thickest films $(t=2.775 \mu \mathrm{m})$, the entire value $(330 \mathrm{MPa})$ arises from microstructural hardening. It is further assumed that microstructural hardening is controlled by the twin spacing (the most strongly varying parameter in Fig. 9 , fit by $d_{t s}=0.38$ $+0.292 t$, with $d_{t s}$ and $t$ in $\mu \mathrm{m}$ ) and obeys a HP relation with $n=0.5, \sigma_{\mathrm{o}}=116 \mathrm{MPa}$ [the limiting value in the fit of the data to Eq. (6)]. This implies a value of $k=233 \mathrm{MPa} \mu \mathrm{m}^{0.5}$. The maximum contribution of the microstructure for different

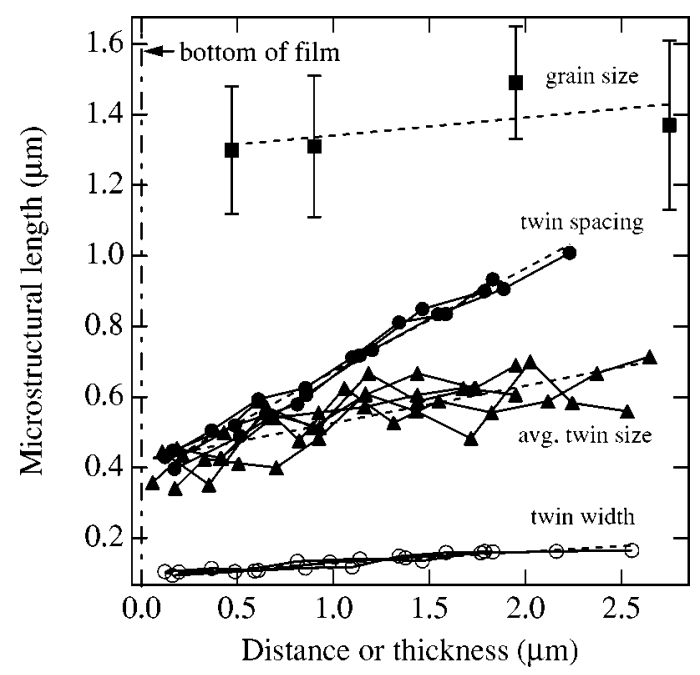

FIG. 9. Average twin size, twin width, and twin spacing vs distance from the bottom of a $2.75 \mu \mathrm{m}$ and a $1.95 \mu \mathrm{m} \mathrm{Cu}$ film. The grain sizes were measured at the top of the films and are plotted as a function of film thickness. The dashed lines are linear fits through each set of data points. 


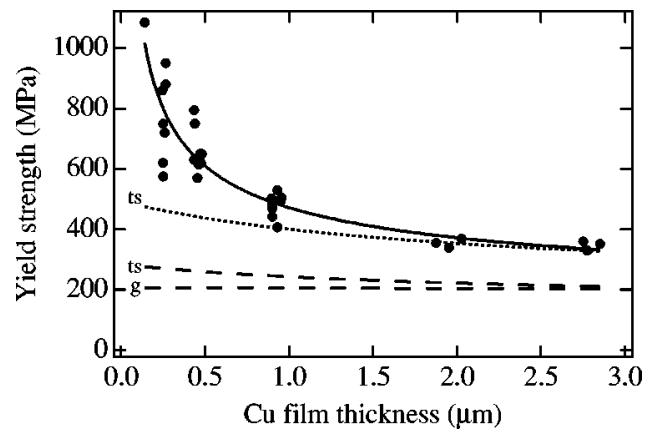

FIG. 10. Contribution to the yield stress of $\mathrm{Cu}$ films on Kapton. The dots are the data points of Fig. 6. The solid line is the fit to the power law of Eq. (6) with $\sigma_{0}=116 \mathrm{MPa}$ and $n=0.473$. The dotted and dashed lines are estimates of, respectively, the maximum and best-estimate HP-type contribution of the microstructure to the yield stress. Curves marked "g" and "ts" are based, respectively, on the grain size or twin spacing measurements of Fig. 9.

film thicknesses was calculated, and is shown as a dotted line in Fig. 10.

The best estimates of microstructural hardening from grain size and twin spacing were computed using, again, $n$ $=0.5$ and $\sigma_{\mathrm{o}}=116 \mathrm{MPa}$, but setting $k=104 \mathrm{MPa} \mu \mathrm{m}^{0.5}$, the latter being an average literature value for polycrystalline $\mathrm{Cu}^{45}$ For the case of grain size, the dependence on thickness is taken to be $d_{g}=1.29+0.051 t$ (the linear fit in Fig. 9 with $d_{g}$ and $t$ in $\mu \mathrm{m}$ ). The results are shown as dashed lines in Fig. 10 .

Figure 11 is a logarithmic plot of the thin-film contribution to the yield stress; that is, the difference between the measured yield stress and the computed microstructural contributions. At the smallest thickness, the film thickness contributes at least half of the value of the yield stress. Even though the Kapton substrate is compliant, it still appears to be a substantial barrier to the motion of dislocations. The slope of the dashed line that corresponds to the twin spacing is $m=0.58$. The exponent is lower than $m=1$ computed from strain gradient plasticity theory. ${ }^{39}$ The discrete dislocation simulations do find an exponent $m=0.5$, but for the

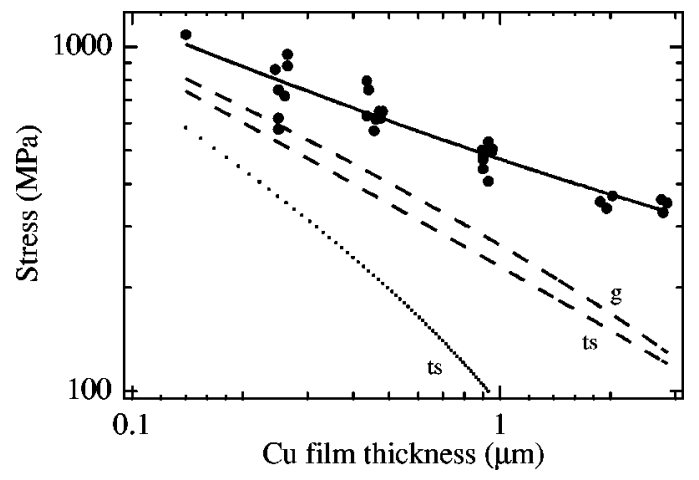

FIG. 11. Contribution of the film thickness to the yield stress. The solid line is the fit through the data. The dashed and dotted lines are the differences in Fig. 10 between the fit through the data and the respective estimates of the HP contribution of the microstructure to the yield stress. The slope of the solid line is -0.473 ; the slope of the dashed line based on grain size ("g") varies from -0.54 for the thinnest films to -0.72 for the thickest ones; the slope of the dashed line based on twin spacing ("ts") is -0.58 . The slope of the dotted line for the thinnest films is -0.82 . thicker films. Nevertheless, inhomogeneous plastic deformation remains the likely cause of the substantial thickness contribution. The effect can be used to estimate the characteristic strain gradient length in these samples. For films of thickness $0.2 \mu \mathrm{m}$, the yield stress is $910 \mathrm{MPa}$ and the contribution from twin space hardening is $270 \mathrm{MPa}$, giving a thickness contribution of $640 \mathrm{MPa}$. According to Eq. (8), this corresponds to a characteristic length $l=0.6 \mu \mathrm{m}$. It should be recognized, of course, that this is a crude estimate, since the functional dependence of Eq. (8) is not observed. Nevertheless, the magnitude of $l$ is similar to that found in torsion, sheet bending, and indentation experiments on metals. ${ }^{46-48}$

\section{CONCLUSIONS}

Microtensile testing with strain sensing by optical diffraction can be used to test metallic thin films as thin as 0.1 $\mu \mathrm{m}$ on compliant polymeric substrates. The grains of the copper films used in these experiments were heavily twinned, but the variation of the microstructural lengths (grain size, twin width, twin spacing) with film thickness was weak. The strong dependence of the yield stress on film thickness must therefore be attributed in large part to a thickness effect, such as that predicted by strain gradient plasticity theory, with a characteristic length on the order of half a micrometer.

\section{ACKNOWLEDGMENTS}

This work was supported by the Department of Energy, Office of Science, Basic Energy Sciences. We thank John Hutchinson for useful discussions.

${ }^{1}$ A. J. Griffith Jr., F. R. Brotzen, and C. F. Dunn, Thin Solid Films 220, 265 (1992).

${ }^{2}$ D. A. Hardwick, Thin Solid Films 154, 109 (1987).

${ }^{3}$ O. Kraft and C. A. Volkert, Adv. Eng. Mater. 3, 99 (2001).

${ }^{4}$ W. D. Nix, Metall. Trans. A 20, 2217 (1989).

${ }^{5}$ H. Huang and F. Spaepen, Acta Mater. 48, 3261 (2000).

${ }^{6}$ D. T. Read and J. W. Dally, J. Mater. Res. 8, 1542 (1993).

${ }^{7}$ R. R. Keller, J. M. Phelps, and D. T. Read, Mater. Res. Soc. Symp. Proc. 338, 227 (1994).

${ }^{8}$ R. R. Keller, J. M. Phelps, and D. T. Read, Mater. Sci. Eng., A 214, 42 (1996).

${ }^{9}$ D. T. Read, Int. J. Fatigue 20, 203 (1998).

${ }^{10}$ D. T. Read, Y.-W. Cheng, R. R. Keller, and J. D. McColskey, Scr. Mater. 45, 583 (2001).

${ }^{11}$ H.-J. Lee, G. Cornella, and J. C. Bravman, Appl. Phys. Lett. 76, 3415 (2000).

${ }^{12}$ R. P. Vinci, G. Cornella, and J. C. Bravman, AIP Conf. Proc. 491, 240 (1999).

${ }^{13}$ F. Macionczyk, W. Brücker, and G. Reiss, Mater. Res. Soc. Symp. Proc. 505, 235 (1998).

${ }^{14}$ F. Macionczyk, W. Brücker, W. Pitschke, and G. Reiss, J. Mater. Res. 13, 2852 (1998)

${ }^{15}$ F. Macionczyk and W. Brücker, J. Appl. Phys. 86, 4922 (1999).

${ }^{16}$ G. Muralidharan, B. Narayanan, C. C. Wong, and M. Manoharan, Mater. Res. Soc. Symp. Proc. 515, 203 (1998).

${ }^{17}$ M. Hommel, O. Kraft, and E. Arzt, J. Mater. Res. 14, 2373 (1999).

${ }^{18}$ M. Hommel and O. Kraft, Acta Mater. 49, 3935 (2001).

${ }^{19}$ P. O. Renault, P. Villain, C. Coupeau, P. Goudeau, and K. F. Badawi, Thin Solid Films 424, 267 (2003).

${ }^{20}$ O. Kraft, M. Hommel, and E. Arzt, Mater. Sci. Eng., A 288, 209 (2000).

${ }^{21}$ P. S. Ho and F. Faupel, Appl. Phys. Lett. 53, 1602 (1988).

${ }^{22}$ F. Faupel, C. H. Yang, S. T. Chen, and P. S. Ho, J. Appl. Phys. 65, 1911 (1989).

${ }^{23}$ S. L. Chiu, J. Leu, and P. S. Ho, J. Appl. Phys. 76, 5136 (1994). 
${ }^{24}$ J. H. Tregilgas and M. Strumpell, Mater. Res. Soc. Symp. Proc. 518, 179 (1998).

${ }^{25}$ Y. S. Kang, P. S. Ho, R. Knipe, and J. Tregilgas, in Thin Films: Stresses and Mechanical Properties VI, edited by W. W. Gerberich, H. Gao, J.-E. Sundgren, and S. P. Baker (Materials Research Society, Pittsburgh, PA, 1997), Vol. 436, p. 35.

${ }^{26}$ J. A. Ruud, D. Josell, F. Spaepen, and A. L. Greer, J. Mater. Res. 8, 112 (1993).

${ }^{27}$ D. Y. W. Yu, PhD thesis, Harvard University, 2003.

${ }^{28} \mathrm{H}$. Huang, PhD thesis, Harvard University, 1998.

${ }^{29}$ D. Heinen, H. G. Bohn, and W. Schilling, J. Appl. Phys. 77, 3742 (1995).

${ }^{30}$ D. Y. W. Yu and F. Spaepen (unpublished).

${ }^{31}$ The points from Kraft et al. on Fig. 5 were taken from their Fig. $4 \mathrm{~b}$ at a plastic strain of $0.2 \%$. The authors report the flow stress at $0.5 \%$.

${ }^{32}$ E. O. Hall, Proc. Phys. Soc. London, Sect. B 64, 747 (1951).

${ }^{33}$ N. J. Petch, J. Iron Steel Inst., London 174, 25 (1953).

${ }^{34}$ J. C. M. Li, Trans. Metall. Soc. AIME 227, 239 (1963).

${ }^{35}$ C. V. Thompson, J. Mater. Res. 8, 237 (1993).

${ }^{36}$ J. D. Embury and J. P. Hirth, Acta Metall. Mater. 42, 2051 (1994).
${ }^{37}$ L. B. Freund, J. Appl. Mech. 54, 553 (1987)

${ }^{38}$ N. A. Fleck and J. W. Hutchinson, Adv. Appl. Mech. 33, 295 (1997).

${ }^{39} \mathrm{~J}$. W. Hutchinson, in Materials Science for the 21 st Century (Society of Materials Science of Japan, Kyoto, Japan, 2001) Vol. A, p. 307.

${ }^{40}$ This equation was obtained by replotting and fitting values reported in Fig. 3 of Ref. 39

${ }^{41}$ L. Nicola, E. Van der Giessen, and A. Needleman, J. Appl. Phys. 93, 5920 (2003).

${ }^{42}$ L. Nicola, E. Van der Giessen, and A. Needleman, Mater. Res. Soc. Symp. Proc. 779, W.5.20.1 (2003).

${ }^{43}$ R. Venkatraman and J. C. Bravman, J. Mater. Res. 7, 2040 (1992).

${ }^{44}$ R.-M. Keller, S. P. Baker, and E. Arzt, J. Mater. Res. 13, 1307 (1998).

${ }^{45}$ R. A. Masumura, P. M. Hazzledine, and C. S. Pande, Acta Mater. 46, 4527 (1998).

${ }^{46}$ N. A. Fleck, G. M. Muller, M. F. Ashby, and J. W. Hutchinson, Acta Metall. Mater. 42, 475 (1994).

${ }^{47}$ J. S. Stölken and A. G. Evans, Acta Mater. 46, 5109 (1998),

${ }^{48}$ M. R. Begley and J. W. Hutchinson, J. Mech. Phys. Solids 46, 2049 (1998) 